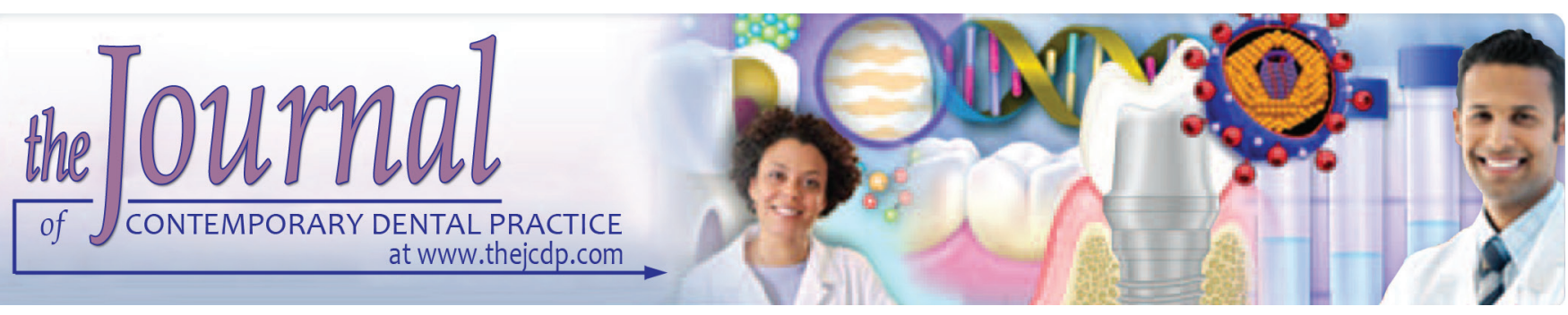

\title{
Effect of Different Irrigation Solutions on the Apical Sealing Ability of Different Single-cone Obturation Systems: An In Vitro Study
}

\author{
${ }^{1}$ Elsayed AM Mohamed, ${ }^{2}$ Shakeri M Fathieh, ${ }^{3}$ Taqipour A Farzaneh, ${ }^{4}$ Barani A Homeira
}

\begin{abstract}
Aim: The aim of this study was to assess the effect of three root canal irrigants on the apical sealing ability of three single-cone obturation systems.

Materials and methods: One hundred maxillary central incisors were selected and their crowns were cut. The roots were divided into three experimental groups of 30 samples each, and one control group of 10 samples ( 5 positives and 5 negatives). Each experimental group was divided equally into three subgroups according to the obturation system. All root canals were instrumented using ProTaper Universal rotary system and irrigated with $3 \%$ sodium hypochlorite (Group 1), $2 \%$ chlorohexidine (Group 2), 3\% hydrogen peroxide (Group 3). Finally, root canals were irrigated with 17\% EDTA followed by distilled water, then obturated with a single-cone technique using gutta-percha/MTA Fillapex (Subgroup A), gutta-percha/ AH Plus (Subgroup B), and Resilon/Relseal SE (Subgroup C). The microleakage was assessed using linear dye penetration method and data were statistically analyzed.
\end{abstract}

Results: Significant differences were found between all groups and subgroups $(p<0.005)$. When $3 \%$ of hydrogen peroxide was used, no leakage was observed with AH Plus sealer, and a high amount of leakage $(5.82 \pm 0.47 \mathrm{~mm})$ was observed with Realseal SE. MTA Fillapex $(0.49 \pm 0.08 \mathrm{~mm})$ and Realseal SE $(1.11 \pm 0.50 \mathrm{~mm})$ showed the lowest amounts of leakage when $2 \%$ chlorohexidine and $3 \%$ sodium hypochlorite were used, respectively.

Conclusion: The type of irrigating solution and obturation system could affect the apical leakage value when single-cone

${ }^{1}$ Department of Restorative Dentistry, College of Dentistry, Ajman University, UAE; Department of Endodontic, Faculty of Dentistry, Mansoura University, Egypt

${ }^{2-4}$ Department of Restorative Dentistry, College of Dentistry, Ajman University, UAE

Corresponding Author: Elsayed AM Mohamed, Department of Restorative Dentistry, College of Dentistry, Ajman University, UAE; Department of Endodontic, Faculty of Dentistry, Mansoura University, Egypt, Phone: 00971505454426, e-mail: elsayednada@yahoo.com obturation technique was used. AH Plus/gutta-percha obturation system showed no apical leakage when root canals were irrigated with $3 \%$ hydrogen peroxide. The using of $2 \%$ chlorohexidine improved sealing ability of MTA Fillapex/gutta-percha. The apical sealing ability of Realseal SE/Resilon decreased when $3 \%$ hydrogen peroxide or $2 \%$ chlorhexidine was used.

Clinical significance: Proper selection of irrigating solutions may positively influence the apical sealing ability of single-cone obturation systems.

Keywords: AH Plus, Irrigating solutions, Microleakage, MTA Fillapex, Realseal SE, Single-cone obturation.

How to cite this article: Elsayed MA, Shakeri FM, Taqipour FA, Barani HA. Effect of different irrigation solutions on the apical sealing ability of different single-cone obturation systems: An in vitro study. J Contemp Dent Pract 2019;20(2):158-165.

Source of support: Nil

Conflict of interest: None

\section{INTRODUCTION}

The aim of a successful root canal treatment is to clean and shape the root canal system for receiving the root canal obturation materials. ${ }^{1}$ However, complete removal of intracanal microorganisms after endodontic instrumentation is very challenging due to the anatomical variations of the root canal system; which limit the access of root canal instruments to all infected areas. ${ }^{2}$ Therefore, different endodontic irrigants have been used to reduce the bacterial load in the infected root canals and simultaneously to remove the smear layer. ${ }^{3}$

Sodium hypochlorite $(\mathrm{NaOCl})$ is the most common endodontic irrigating solution that has an excellent organic tissue solvent and antimicrobial effect. However, $\mathrm{NaOCl}$ is toxic when used at high concentration, and serious mishaps could result from its inappropriate use. ${ }^{4}$ Chlorhexidine gluconate ( $\mathrm{CHX}$ ) is another irrigating solution that can be used to disinfect the root canals. ${ }^{5}$ 
Hydrogen peroxide $\left(\mathrm{H}_{2} \mathrm{O}_{2}\right)$ in $3 \%$ concentration has also been used as an intracanal irrigation solution because it has antimicrobial activity against various microorganisms such as viruses, bacteria, yeasts, and even bacterial spores. ${ }^{5}$ Most of the previously mentioned irrigating solutions have not any effect on inorganic components of the smear layer that is formed after the root canal instrumentation. ${ }^{3}$ Therefore, it was recommended to use $17 \%$ ethylenediaminetetraacetic acid (EDTA) as a last irrigation solution to remove the smear layer and improve the quality of adhesion and sealing capacity of root canal sealers. ${ }^{4}$

Irrigant solutions may cause chemical and structural changes in dentin that could affect the adhesion of obturation materials, specially bonded materials, to dentin surface..$^{6-8}$ It has been demonstrated that sodium hypochlorite solution, hydrogen peroxide solution, or a combination of both, cause deep changes in the collagen structure by dehydration and/or removal of fibrils that form the hybrid layer, thus reducing monomer penetration into dentin, and consequently bond strength. ${ }^{6}$ The release of oxygen originating from substances applied to the root canal should also be considered since it acts as an inhibitor of polymerization. ${ }^{7}$ It has been also shown that the using of CHX could improve the integrity of the hybrid layer and resin-dentin bond stability. ${ }^{8}$

Although different obturation techniques are currently available, there is on-going interest in developing more effective and simplified materials and/or techniques. Nowadays, single-cone obturation technique has become popular with the widespread use of rotary NiTi instruments. ${ }^{9}$ It was found that the single-cone obturation technique produced sealing ability similar to the other obturation techniques. ${ }^{9}$

The selection of an appropriate sealer will influence the clinical outcome of endodontic therapy. ${ }^{10} \mathrm{AH}$ Plus (Dentsply Maillefer, Ballaigues, Switzerland) is the most frequently epoxy resin-based sealer used because of its good physical and chemical properties and good sealing ability ${ }^{11}$ With the aim of improving the marginal sealing properties of root canal filling, new root canal filling systems have been developed, such as Realseal SE system, which may encourage the practitioners to use the single-cone obturation technique. The Reaseal SE system consists of a self-etching methacrylate sealer and Resilon core material. It is claimed to simplify the application steps of the ordinary epiphany system, making it user-friendly material. In addition, it bonds to both the Resilon core and radicular dentin through hybrid layer on both substrates leading to the formation of a monoblock unit, which may prevent leakage and improve the root strength. ${ }^{12}$ MTA Fillapex is a new sealer developed by Angelus (Londrina/Parana/Brazil) and composed of Portland cement, bismuth oxide, and dehydrated calcium sulfate. The manufacturer claims that this type of sealer can provide perfect sealing ability and promotes cementum regeneration. ${ }^{13}$

Most of the endodontic failures are caused by the microleakage resulting from incomplete obturation. ${ }^{1}$ Therefore, leakage tests are important in evaluating the excellence of endodontic treatment. Passive dye penetration method is the most widely used because of its sensitivity, ease of use and convenience. ${ }^{14}$

The purpose of this study was to evaluate the influence of $3 \%$ sodium hypochlorite, $2 \%$ chlorhexidine and $3 \%$ hydrogen peroxide on the apical microleakage of three matched-taper single-cone root canal filling systems: Gutta-percha/MTA Fillapex, Gutta-percha/ AH Plus, and Resilon/ Realseal SE. The null hypothesis of the current study was the sealing ability of these different obturation systems will not be affected by the type of irrigation solution.

\section{MATERIALS AND METHODS}

\section{Samples Grouping and Root Canal Preparation}

One hundred maxillary central incisors were divided into three experimental groups ( $\mathrm{n}=30 \mathrm{each}$ ) according to the type of irrigating solution, and two control groups of five samples each. Each experimental group was divided into three subgroups of 10 samples each according to the type of root canal sealer (Table 1).

The crowns were sectioned and the length of roots was standardized at $14 \pm 1 \mathrm{~mm}$. The size of the initial file for each sample was $0.25 \mathrm{~mm}$ or less. After determination the working lengths, root canals were instrumented with ProTaper Universal rotary system (Dentsply Maillefer, Ballaigues, Switzerland), until reaching to a master apical file of size F4. Between files, root canals were irrigated with $5 \mathrm{~mL}$ of the following irrigating solutions: $3 \%$ Sodium hypochlorite (Group 1), 2\% Chlorohexidine (Group 2), and 3\% Hydrogen peroxide (Group 3). Finally, all canals were irrigated with $5 \mathrm{~mL}$ of $17 \%$ EDTA solution (MD-Cleanser, META BIOMED Co. Ltd, Korea) for 1 minute, followed by $5 \mathrm{~mL}$ distilled water as final irrigation. The irrigation was performed using a 27-gauge Max-i-Probe needle (Dentsply Maillefer, Ballaigues, Switzerland).

\section{Root Canal Obturation}

Before obturation, a size \#10 finger spreader (Mani Inc., Tocigi-Ken, JA) was inserted externally from the apical direction into the apical foramen $(0.5 \mathrm{~mm})$ of each sample in the experimental and positive control groups. With the 
Table 1: Experimental samples grouping.

\begin{tabular}{llll}
\hline Groups $(\mathrm{N})$ & Subgroups $(\mathrm{N})$ & Core material & Root canal sealer \\
\hline Group 1 & & & \\
$3 \%$ Sodium hypochlorite $(\mathrm{N}=30)$ & Subgroup A $(\mathrm{N}=10)$ & Single-cone gutta-percha & MTA Fillapex \\
& Subgroup B $(\mathrm{N}=10)$ & Single-cone gutta-percha & AH Plus \\
& Subgroup C $(\mathrm{N}=10)$ & Single-cone Realseal & Realseal SE \\
\hline Group 2 & & & \\
$2 \%$ Chlorohexidine $(\mathrm{N}=30)$ & Subgroup A $(\mathrm{N}=10)$ & Single-cone gutta-percha & MTA Fillapex \\
& Subgroup B $(\mathrm{N}=10)$ & Single-cone gutta-percha & AH Plus \\
& Subgroup C $(\mathrm{N}=10)$ & Single-cone Realseal & RealSeal SE \\
\hline Group 3 & & & \\
$3 \%$ Hydrogen peroxide $(\mathrm{N}=30)$ & Subgroup A $(\mathrm{N}=10)$ & Single-cone gutta-percha & MTA Fillapex \\
& Subgroup B $(\mathrm{N}=10)$ & Single-cone gutta-percha & AH Plus \\
& Subgroup C $(\mathrm{N}=10)$ & Single-cone Realseal & Realseal SE \\
\hline
\end{tabular}

exception of the coronal surface and apical foramen, all external surfaces of roots were coated with three layers of nail varnish. Each layer was left to dry before applying the next layer of varnish. After complete setting of varnish, the finger spreader was gently removed keeping the apical foramen open. In the negative control group: all root surfaces were coated with nail varnish, similar to the experimental groups, including the apical foramen.

Roots were filled using single-cone obturation technique with ProTaper gutta-percha size F4/MTA Fillapex (Subgroup A), ProTaper gutta-percha size F4/ AH Plus (Subgroup B) or Resilon point size 40/0.06 with Realseal SE (Subgroup C). The root canal sealer was applied into each canal using a \#30 Lentulo spiral rotated at $300 \mathrm{rpm}$ and $3 \mathrm{~mm}$ away from the apex. The tip of the prefitted master cone was coated with a thin layer of sealer and inserted into the canal to its full working length using up and down slow pumping motion. The coronal excess of gutta-percha and Resilon was seared off using a heated endodontic plugger, and the excess sealer was removed using a gauze wetted with distilled water. The coronal surface of each sample filled with Resilon/ Realseal SE was light-cured for 40 seconds with an LED curing light (Litex ${ }^{\mathrm{TM}}$ 696, Dentamerica®, USA). The quality of obturation was assessed radiographically, and samples with insufficient obturation were excluded from the study and replaced with new ones. After finishing obturation, the coronal surface of each root was sealed with light-cured glass ionomer cement and coated with three layers of nail varnish. All samples were incubated for 1 week at $37^{\circ} \mathrm{C}$ and $95 \%$ humidity to allow complete setting of sealers.

\section{Microleakage Assessment}

All samples were placed in $2 \%$ methylene blue dye and stored for 72 hours, after which they were thoroughly rinsed under running tap water and the nail varnish was removed with a scalpel blade no. 11. The apical
$7 \mathrm{~mm}$ of each root was longitudinally sectioned in a buccolingual direction, and then a horizontal cut was made on the mesial or distal surface using a flexible diamond disc under water coolant. The apical $7 \mathrm{~mm}$ of the proximal portion of each sample was cut to expose the filling material that was then removed using an endodontic explorer to allow better evaluation of dye penetration.

Microleakage in each sample was evaluated under a digital stereomicroscope (Leica EZ4W, Germany) at 20 $X$ magnification. Pictures were captured, saved, and the maximum apical dye penetration leakage was measured (Fig. 1) using ImageJ software (National Institutes of Health, Bethesda, MD, USA). In order to eliminate the operator variable, a single operator completed all preparations and testing procedures.

\section{Statistical Analysis}

The results were statistically analyzed by one-way ANOVA and Tukey's or Games-Howell's post hoc tests using IBM SPSS version 20 (IBM Corporation 1 New

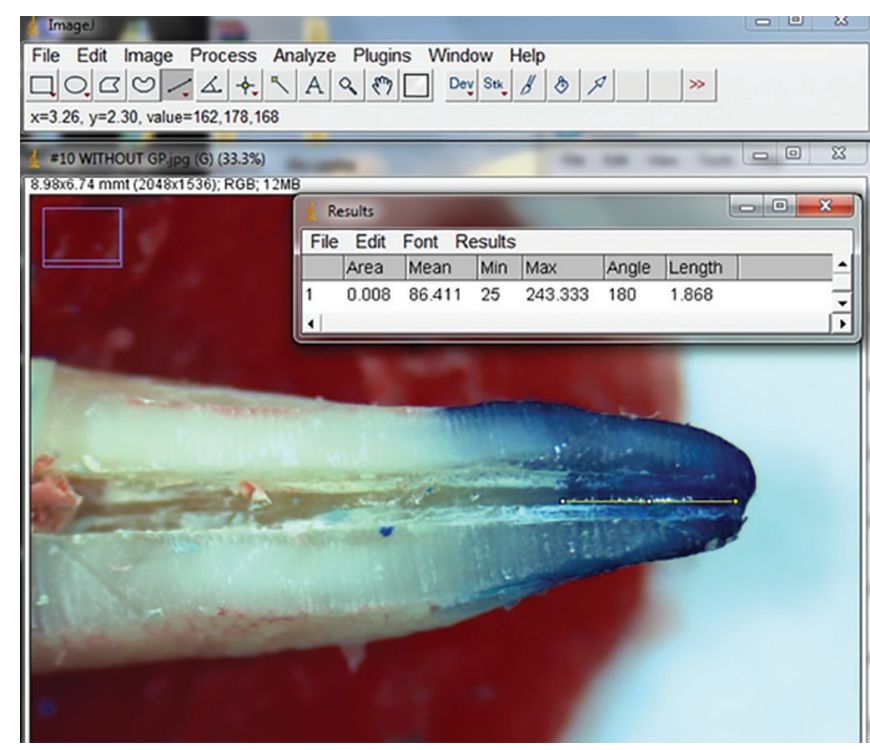

Fig. 1: Measurement of linear dye leakage using image J software 
Table 2: Comparison of mean apical leakage values for the experimental groups and subgroups (mm).

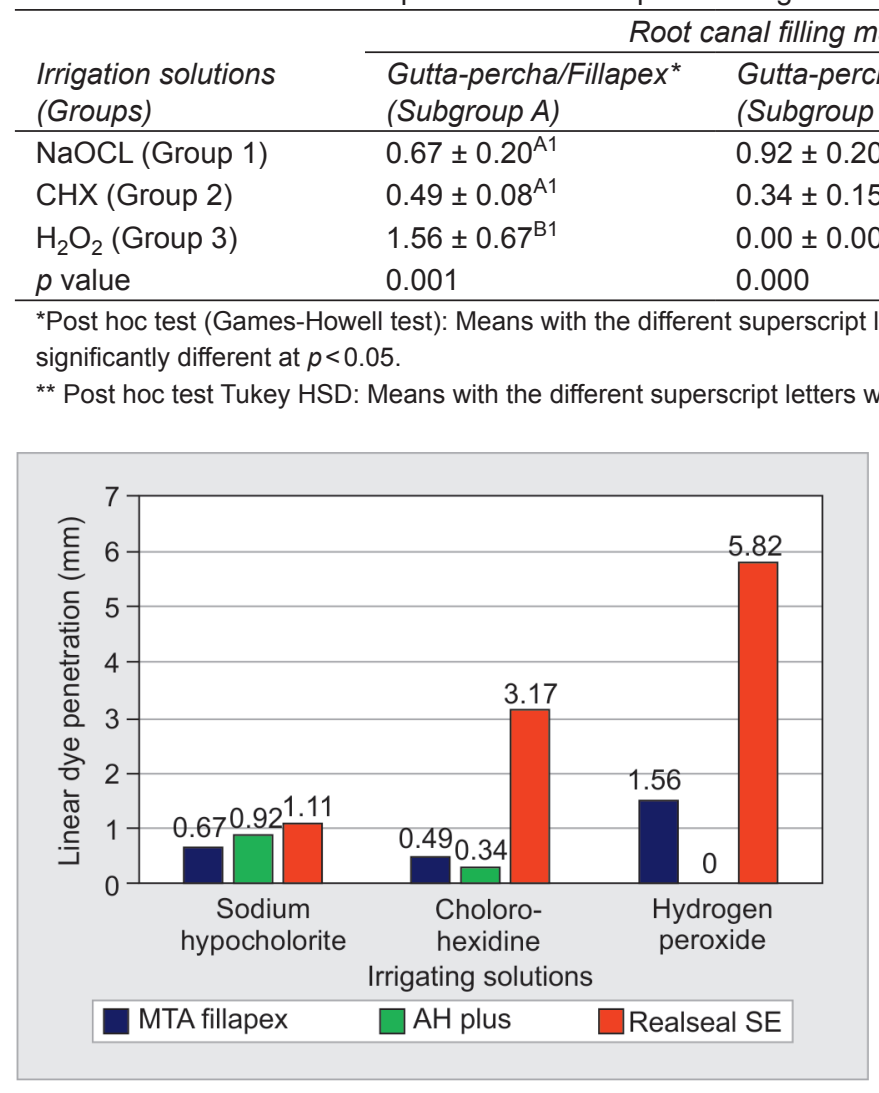

Fig. 2: Graphic presentation of the mean values of apical linear dye penetration for experimental single-cone obturation systems after using different irrigating solutions

Orchard Road Armonk, New York, USA). All the level of statistical significance was set at $p<0.05$.

\section{RESULTS}

The mean values and standard deviations of the apical dye leakage are presented in Table 2 and illustrated in Figure 2. The results of the two-way ANOVA test (Table 3) showed that the type of irrigating solution and the root canal filling system $(p \leq 0.001)$ affected significantly the apical dye leakage of obturated samples. The positive-control specimens demonstrated maximum dye penetration of the root canal system whilst the negative control specimens had no dye penetration into the roots. All experimental subgroups in each group demonstrated apical leakage of variable measurements (Fig. 3) except subgroup B of the third group that showed no apical leakage.
When the irrigating solutions were compared regarding their effect on the apical sealing ability of each obturation system (Table 2), there were significant differences between them ( $p \leq 0.001)$. MTA Fillapex/gutta-percha (Subgroup A) exhibited the lowest apical leakage mean value $(0.49 \pm 0.08$ $\mathrm{mm}$ ) when CHX irrigation solution was used. However, there was no statistically significant difference between the effect of CHX and NaOCL on the apical sealing ability of Gutta-percha/MTA Fillapex. Gutta-percha/AH Plus (Subgroup B) did not show any apical dye leakage when $\mathrm{H}_{2} \mathrm{O}_{2}$ irrigating solution was used and showed the highest apical leakage $(0.92 \pm 0.20 \mathrm{~mm})$ when NaOCL irrigation solution was used. Resilon/Realseal SE (Subgroup C) exhibited the lowest mean leakage value $(1.11 \pm 0.50 \mathrm{~mm})$ when $\mathrm{NaOCL}$ irrigation solution was used, and the highest mean leakage value when $\mathrm{H}_{2} \mathrm{O}_{2}$ was used.

When the apical sealing abilities of root canal sealers were compared (Table 2) after using each irrigating solution, there were significant differences between them $(p \leq 0.01)$. When NaOCL was used, gutta-percha/MTA Fillapex showed the lowest mean leakage value $(0.67 \pm$ $0.20 \mathrm{~mm}$ ). When $\mathrm{CHX}$ was used, gutta-percha/AH Plus showed the lowest mean leakage value $(0.34 \pm 0.15 \mathrm{~mm})$ but without a statistically significant difference when compared with gutta-percha/MTA Fillapex $(0.49 \pm 0.08$ $\mathrm{mm}$ ). When $\mathrm{H}_{2} \mathrm{O}_{2}$ was used, AH Plus showed no leakage, while Resilon/Realseal SE showed the highest leakage mean value $(5.82 \pm 0.74 \mathrm{~mm})$.

\section{DISCUSSION}

The development and maintenance of the sealing of the root canal system is the key to successful root-canal treatment. To obtain a hermetic apical seal, different

Table 3: Statistical results of Univariate Analysis of Variance (two-way ANOVA) that determine the effect of irrigation and obturating material types on the apical leakage of experimental samples.

\begin{tabular}{llllll}
\hline Source & Sum of squares & $d f$ & Mean square & $F$ & Sig. \\
\hline Type of irrigating solution (X1) & 38.82 & 2 & 19.41 & 108.64 & 0.000 \\
Type of obturation materials (X2) & 149.50 & 2 & 74.75 & 418.40 & 0.000 \\
Irrigation type * Obturation materials & 83.383 & 4 & 20.85 & 116.68 & 0.000 \\
Error & 97.85 & 85 & 1.15 & & \\
\hline Total & 506.02 & 90 & & \\
\hline
\end{tabular}



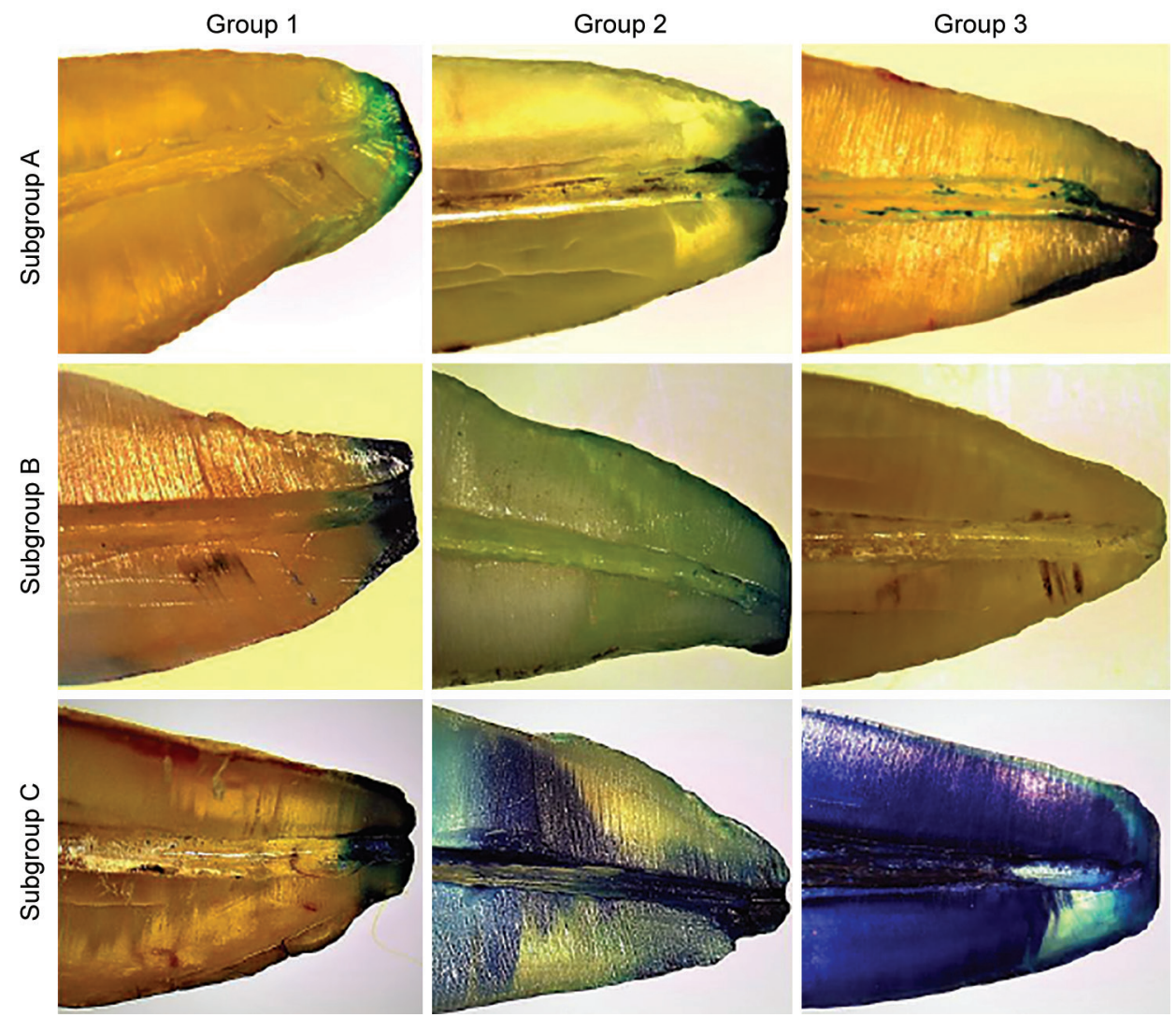

Fig. 3: Apical dye leakage of selected samples in different experimental groups and subgroups

obturation materials and techniques were introduced and evaluated. Until now, there is no particular material or technique that is able to completely prevent apical leakage. However, with the introduction of greater taper rotary nickel-titanium files and matched taper and size of core materials, single-cone obturation technique becomes popular among dentists. ${ }^{9}$ This technique is simple, fast, and can be performed without sophisticated equipment. The sealing ability of this technique depends on the quality of root canal sealer, which is important to achieve immediate and long-lasting seal along the root canal wall. ${ }^{10}$

Wide varieties of endodontic sealers are used with gutta-percha. These sealers are grouped based on their prime constituent or structure, such as zinc oxide eugenol, calcium hydroxide, glass ionomer, and resin sealer. In the current study, three types of root canal sealers were used: AH Plus, MTA Fillapex, and Realseal SE. AH Plus has a good physical and chemical properties as well as good sealing ability. It is considered the gold standard to which other types of root canal sealers are compared. ${ }^{11}$ The Reaseal SE system was claimed to be a more user-friendly material that bond to both the Resilon core and radicular dentin through hybrid layers on both substrates leading to a monoblock unit, which may prevent leakage and improve the root strength. ${ }^{12}$ MTA Fillapex is a new MTA-based sealer, which has excellent biocompatibility, bioactivity, osteoconductivity, and perfect seal. ${ }^{13}$

Leakage studies on the sealing properties of endodontic materials are still important and relevant. Therefore, the aim of the current study was to study the effect of $3 \% \mathrm{NaOCl}, 2 \% \mathrm{CHX}$ and $3 \% \mathrm{H}_{2} \mathrm{O}_{2}$ on the apical dye leakage of the following single-cone obturation systems: ProTaper gutta-percha/MTA Fillapex, ProTaper Gutta-percha/AH Plus, and Resilon/Realseal SE.

Using extracted human teeth in the current study introduced variabilities, which closely simulate the clinical situations. In this study, extracted maxillary incisors with nearly similar apical diameters (size \#25) and root length, were selected and instrumented to \# F4 ProTaper universal nickel-titanium rotary instrument. Therefore, variables such as anatomical variations, canal size and the diameter of the apical foramen, which can affect the apical leakage, were minimized. Moreover, the rotary instrumentation was found to be less time consuming, more comfortable and more efficient than hand instrumentation. ${ }^{14}$

During instrumentation, samples in each group were irrigated only with one of the experimental irrigation solution, and the last irrigant was always 17\% EDTA to remove smear layer, which is followed by distilled water to remove any traces of irrigation solutions. This allowed evaluating the effect of each irrigant type on the sealing 
ability of the particular single-cone obturation system. The maintenance of the apical patency of root canals after finishing instrumentation is important to avoid the blocking of the apical foramen with a dentinal plug that could influence the results of dye leakage penetration.

In this study, methylene blue dye penetration method was selected to evaluate the apical microleakage because it is inexpensive and easy to manipulate. ${ }^{15}$ In addition, it has a high degree of staining capability and a molecular weight lower than that of bacterial toxins. ${ }^{16}$ In spite of these advantages, the in vitro penetration of dyes into root canals should not be directly compared with the in vivo leakage of irritants. Instead, results of these tests should be considered as indicators for leakage probability, because a filling material that does not allow leakage of small molecules, such as dyes, can prevent leakage of larger molecules, such as bacteria and/or their byproducts. ${ }^{16}$

Positive and negative controls were used to test the experimental system. The positive control group showed the highest level of dye penetration, indicating that sealing ability of single-cone gutta-percha deteriorates when used without a root canal sealer. On the other hand, the negative control group did not show any apical leakage and this confirms the sealing quality of nail varnish and indicates that leakage occurred only through the apical foramen.

The null hypothesis of the current study was rejected because the results showed that the type of irrigating solution significantly affected the sealing ability of experimental single-cone obturation systems.

One interesting result in the current study was the absence of apical dye leakage when the hydrogen peroxide solution was used as an irrigant with ProTaper guttapercha/AH Plus single-cone obturation system. Up to our knowledge, there is no study indicating that AH Plus sealer could prevent the apical leakage when used with any irrigation protocol. However, previous studies showed that AH Plus sealer, when used with gutta-percha and different obturation techniques under different irrigation protocols, showed better apical seal compared with other types of sealers. ${ }^{11}$ The good apical sealing ability of AH Plus was explained by its good adhesiveness, its ability to penetrate into micro-irregularities of the dentinal wall, its setting expansion, and its ability to form a covalent bond with amino groups of exposed radicular dentin collagen.11,17 The role of $\mathrm{H}_{2} \mathrm{O}_{2}$ in preventing apical dye leakage of $\mathrm{AH}$ Plus when used with single-cone gutta-percha was not previously evaluated. However, the presence of oxygen liberated from the dissociation of hydrogen peroxide when in contact with organic debris could improve the adhesion of AH Plus sealer by increasing the permeability of dentin and enhance its chemical bond with amino groups of exposed dentin collagen. ${ }^{18}$ Moreover, the use of
EDTA after $\mathrm{H}_{2} \mathrm{O}_{2}$ will increase the wettability of the dentin surface and remove the smear layer that allows more sealer penetration into dentinal tubules and increases interfacial adaptation of sealer. ${ }^{19}$ The greatest mean dye leakage value was observed when hydrogen peroxide irrigation was used with Resilon/Realseal SE obturation system. This may be attributed to the polymerization shrinkage and high C-factor associated with methacrylate resin-based sealer. ${ }^{20}$ Moreover, the oxygen release within the root canals because of hydrogen peroxide dissociation could inhibit the polymerization of resins and decrease their bond strength with radicular dentin, which increases the likelihood of microleakage. ${ }^{7}$ Moreover, hydrogen peroxide and EDTA have the ability to reduce the microhardness of radicular dentin, which could compromise the adhesion, and sealing ability of dentin bonding materials to the softened chemically treated dentin surfaces. ${ }^{21}$

When $\mathrm{NaOCl}$ was used as an irrigating solution, guttapercha/mTA Fillapex showed significantly lower leakage mean value when compared with gutta-percha/AH Plus and Resilon filling systems. This could be due to its greater penetration depth into the dentinal tubules and setting expansion. ${ }^{22}$ Regarding methacrylate-based sealers, its bonding capability to radicular dentin may be relatively affected by oxidizing property of $\mathrm{NaOCl}$ that interferes with the initiation of the interfacial polymerization of resin sealers, leading to lower bond strengths. ${ }^{23}$ Moreover, $\mathrm{NaOCl}$ can damage the organic components of dentin, mainly through collagen dissolution, and can hinder the formation of a consistent hybrid layer, which is important for resin-bonded sealers. ${ }^{7}$ The polymerization shrinkage of Resilon system and high $C$ factor could also affect the dentin bonding ability of this system. ${ }^{20}$ Gutta-percha/ AH Plus obturation system showed lower apical leakage than that of Resilon, but without statistically significant difference, when $\mathrm{NaOCl}$ was used. This may be due to the better interfacial adaptation of AH Plus with radicular dentin. ${ }^{11}$ These results are in consistency with a previous study that showed no differences between gutta-percha/ AH Plus and Resilon/Epiphany sealer. ${ }^{24}$ However, some authors ${ }^{25}$ concluded that Resilon/Epiphany sealer had better apical sealing ability than gutta-percha/AH-Plus sealer while others ${ }^{26}$ concluded that Epiphany and Resilon leaked significantly more than gutta-percha and $\mathrm{AH}$ Plus. The causes of these discrepancies may be related to differences in the methodologies used.

It was found that $\mathrm{CHX}$ solution did not affect the bond strength of resin-based sealers and improved the adhesion of hydrophilic bonded materials such as methacrylate-based sealers. ${ }^{8}$ One study found that chlorohexidine can improve the integrity of the hybrid layer and the resin-dentin bond stability. ${ }^{8}$ However, the present findings showed that the sealing ability of $\mathrm{AH}$ 
Plus was higher than that of MTA Fillapex but without significant difference, while their sealing ability was higher than that of the Resilon system. This is because the $\mathrm{CHX}$ has a harmless effect on the micro-hardness and roughness of root canal dentin, ${ }^{21}$ which is important for adhesion of root canal sealers. The presence of surface surfactant in CHX solution could also increase the dentin surface energy and its wettability to root canal sealers. ${ }^{27}$ The strong and long-lasting antimicrobial and low toxic effect of CHX in comparison with $\mathrm{NaOCl}$, support the use of $\mathrm{CHX}$ as an irrigant solution. ${ }^{5}$

The present results revealed that CHX irrigating solution decreased the sealing ability of Resilon system, which is in accordance with Bodrumlu et al. who found that the apical sealing ability of Epiphany SE root canal sealers decreased when the chlorhexidine was used as an irrigation solution. ${ }^{28}$ The deteriorating effect of $\mathrm{CHX}$ on the sealing ability of Resilon system may be due to its inability to remove organic components of the smear layer $^{5}$ and the presence of a surfactant which may interfere with polymerization of the methacrylate-based sealer which is important for dentin bonding mechanism. The polymerization shrinkage of methacrylate-based sealer and high C-factor may be considered as additional factors that could negatively affect adhesion and sealing ability of Resilon system. ${ }^{20}$

The using of hydrogen peroxide as an irrigating solution decreased the sealing ability of Gutta-percha/ MTA Fillaex when compared with $\mathrm{NaOCl}$ and $\mathrm{CHX}$. This may be explained by the retardation effect of the oxygen within dentinal tubules on the setting of MTA Fillapex and the formation of voids at the interfacial layer between dentin and the sealer that badly affects the interfacial bond strength and adhesion of the sealer.

The results of the current study are limited to the obturated canals of maxillary central incisors. Further laboratory and clinical studies must be conducted to investigate the effect of $3 \%$ hydrogen peroxide as single or combined irrigating solution on the sealing ability of currently available root canal sealers to confirm the current results especially for AH Plus root canal sealer.

\section{CONCLUSION}

Within the limitations of the current study, the following conclusions can be drawn:

- The type of irrigating solution affected significantly the apical sealing ability of all experimental root canal sealers.

- Gutta-percha/AH Plus single-cone obturation system showed no apical leakage when used after irrigation with $3 \% \mathrm{H}_{2} \mathrm{O}_{2}+17 \%$ EDTA.
- Gutta-percha/MTA Fillapex single-cone obturation system showed a better apical seal when used after irrigation with $2 \% \mathrm{CHX}$ or $3 \% \mathrm{NaOCl}+17 \%$ EDTA than when used after irrigation with $3 \% \mathrm{H}_{2} \mathrm{O}_{2}+17 \%$ EDTA.

- Resilon/Realseal SE single-cone obturation system showed better apical seal when used after irrigation with $3 \% \mathrm{NaOCl}+17 \%$ EDTA than when used after irrigation with $2 \% \mathrm{CHX}$ or $3 \% \mathrm{H}_{2} \mathrm{O}_{2}+17 \%$ EDTA

\section{CLINICAL SIGNIFICANCE}

The clinician must be aware of the effect of irrigation solution on the sealing ability of root canal sealers especially when used with single-cone obturation technique. It is advisable to use $3 \%$ of hydrogen peroxide with AH Plus root canal sealer but not with MTA Fillapex or Realseal SE. Sodium hypochlorite solution can be used when MTA Fillapex or Realseal SE are used.

\section{REFERENCES}

1. Nair PN. Pathogenesis of apical periodontitis and the causes of endodontic failures. Crit Rev Oral Biol Med 2004;15: 348-381.

2. Gu LS, Kim JR, Ling J, Choi KK, Pashley DH, Tay FR. Review of contemporary irrigant agitation techniques and devices. J Endod 2009; 35:791-804.

3. Haapasalo M, Shen Y, Qian W, Gao Y. Irrigation in endodontics. Dent Clin North Am 2010;54:291-312.

4. Mohammadi Z. Sodium hypochlorite in endodontics: an update review. Int Dent J 2008; 58:329-341.

5. Basrani B, Lemonie C. Chlorhexidine gluconate. Aust Endod J 2005;3:48-52.

6. Torneck CD, Titley KC, Smith DC, Adibfar A. The influence of time of hydrogen peroxide exposure on the adhesion of composite resin to bleached bovine enamel. J Endod 1990; 16:123-128.

7. Ozturk B, Özer F. Effect of $\mathrm{NaOCl}$ on bond strengths of bonding agents to pulp chamber lateral walls. J Endod 2004;30: 362-365.

8. Carrilho MR, Geraldeli S, Tay F, de Goes MF, Carvalho RM, Tjäderhane L, Reis AF, Hebling J, Mazzoni A, Breschi L, Pashley D. In vivo preservation of the hybrid layer by chlorhexidine. J Dent Res 2007;86:529-533.

9. Taşdemir T, Er K, Yildirim T, Buruk K, Celik D, Cora S, Tahan E, Tuncel B, Serper A. Comparison of the sealing ability of three filling techniques in canals shaped with two different rotary systems: a bacterial leakage study. Oral Surg Oral Med Oral Pathol Oral Radiol Endod 2009;108:129-134.

10. Orstavik D, Kerekes K, Eriksen HM. Clinical performance of three endodontic sealers. Endod Dent Traumatol 1987;3: 178-186.

11. Sevimay S, Kalayci A. Evaluation of apical sealing ability and adaptation to dentine of two resin-based sealers. J Oral Rehabil. 2005;32:105-110.

12. Babb BR, Loushine RJ, Bryan TE, Ames JM, Causey MS, Kim J, Kim YK, Weller RN, Pashley DH, Tay FR. Bonding of self- 
adhesive (self-etching) root canal sealers to radicular dentin. J Endod 2009; 35:578-582.

13. Sonmez I, Oba A, Sonmez D, Almaz M. In vitro evaluation of apical microleakage of a new MTA-based sealer. Eur Arch Paediatr Dent 2012;5:252-255.

14. Aguiar CM, Mendes Dde A, Câmara AC, Figueiredo AP. Assessment of canal walls after biomechanical preparation of root canals instrumented with Protaper Universal rotary system. J Appl Oral Sci 2009;17:590-595.

15. Veríssimo DM, do Vale MS. Methodologies for assessment of apical and coronal leakage of endodontic filling materials: a critical review. J Oral Sci 2006;48:93-98

16. Oliver CM, Abbott PV. Correlation between clinical success and apical dye penetration. Int Endod J 2001;34:637-644.

17. Marciano MA, Guimarães BM, Ordinola-Zapata R, Bramante CM, Cavenago BC, Garcia RB, Bernardineli N, Andrade FB, Moraes IG, Duarte MA. Physical properties and interfacial adaptation of three epoxy resin-based sealers. J Endod 2011; 37:1417-1421.

18. Cohen S, Stewart GG, Laster LL. The effects of acids, alkalies, and chelating agents on dentine permeability. Oral Surg Oral Med Oral Pathol 1970; 29:631-634.

19. Froes JAV, Horta HGP, Silveria AB. Smear layer influence on the apical seal of four different obturation techniques. J Endod 2000; 26:351-354.

20. Souza SFC, Bombana AC, Francci C, Gonçalves F, Castellan C, Braga RR. Polymerization stress, flow and dentine bond strength of two resin-based root canal sealers. Int Endod J 2009; 42:867-873.
21. Ari H, Erdemir A and Belli S. Evaluation of the effect of endodontic irrigation solutions on the microhardness and the roughness of root canal dentin. J Endod 2004; 30: 792-795.

22. Nikhil V, BansalP, SawaniS. Effect of technique of sealer agitation on percentage and depth of MTA Fillapex sealer penetration: A comparative in-vitro study. J Conserv Dent 2015;18:119-123.

23. Turker SA, Yilmaz Z, Ozcelik B, Gorduysus M, Altundasar E. Effects of ultrasonically activated irrigants with or without surfactant on smear layer removal after post space preparation. J Clin Exp Dent 2012; 4:260-265.

24. Fransen JN, He J, Glickman GN, Rios A, Shulman JD, Honeyman A. Comparative assessment of ActiV GP/glass ionomer sealer, Resilon/Epiphany, and gutta-percha/AH plus obturation: a bacterial leakage study. J Endod 2008; 34:725-727.

25. Fathia E, Hassan Abu-bakr N, Yahia I. A Comparative Study of the Microleakage of Resilon/Epiphany and GuttaPercha/AH-Plus Obturating Systems. Iran Endod J 2012;7: 139-143.

26. Stratton RK, Apicella MJ, Mines P. A fluid filtration comparison of gutta-percha versus Resilon, a new soft resin endodontic obturation system. J Endod 2006;32:642-645.

27. Assis DF, Prado M, Simão RA. Evaluation of the interaction between endodontic sealers and dentin treated with different irrigant solutions. J Endod 2011;37:1550-1552.

28. Bodrumlu E, Parlak E, Bodrumlu EH. The effect of irrigation solutions on the apical sealing ability in different root canal sealers. Braz Oral Res 2010;24:165-169. 